\title{
Influências paleoclimáticas na gênese do carste de Tejuçuoca, NE do Brasil
}

\author{
Paleoclimatic influences in the karst genesis of Tejuçuoca, NE Brazil
}

\author{
Cavalcante $^{1}$, D. R.; Bastos ${ }^{2}$, F. H. \\ daniel_reiscl@hotmail.com
}

\begin{abstract}
Resumo
No município de Tejuçuoca, centro-norte do Ceará, se encontra uma das mais significativas ocorrências de relevos cársticos do Estado. O referido estudo tem por objetivo tentar explicar a gênese da atual configuração do carste, associando-o a processos morfodinâmicos atuais e pretéritos. Para isso, foram divididas as etapas de trabalho em levantamentos bibliográficos/cartográficos, levantamentos de campo seguidos de trabalhos de gabinete com auxilio de técnicas de geoprocessamento e por fim a integralização dos dados obtidos. $\mathrm{O}$ significativo desenvolvimento de feições de dissolução não corresponde com as condições climáticas atuais semiáridas, sendo, portanto, sugerido que tais formas tiveram seu ápice de desenvolvimento em condições climáticas mais úmidas durante o Quaternário que, posteriormente, passou a apresentar climas mais secos viabilizando ciclos erosivos através de processos físicos condizentes com o entorno do carste. Nessa perspectiva foram identificadas feições exocársticas e endocársticas que tiveram sua gênese ligada aos eventos paleoclimáticos, são exemplos os lapiás alveolares e os diferentes espeleotemas encontradas nas cavernas.
\end{abstract}

Palavras-chave: Gemorfologia Cárstica. Paleoclima. Semiárido Brasileiro.

\begin{abstract}
In the municipality of Tejuçuoca, north-central Ceará, is one of the most significant occurrences of karst reliefs $i$ this state. The study aims to try to explain the genesis of the current karst configuration, associating it with the present and preterits morphodynamic processes. For this, the work steps were divided into bibliographic/cartographic surveys, field work and office work with the help of GIS techniques and finally the integralization of the data. The significant development of dissolution features does not correspond with the current weather semiarid conditions. Thus, it is believed that these forms had its maximum development in more humid weather conditions during the Quaternary, which subsequently began to show drier climates allowing erosive cycles through physical processes as can be seen in the surrounding karst. In this perspective were identified exokarstic and endokarstic features that had its origin linked to the paleoclimatic events. Among these karst features, we highlight the lapiez and different speleothems found in the caves.
\end{abstract}

Keywords: Carstic Geomorphology. Paleoclimate. Brazilian semiarid region.

\section{INTRODUÇÃO}

Kohler (1989) define relevo cárstico como um relevo que se desenvolve sobre rochas solúveis, com predomínio de processos corrosivos através das águas superficiais e subterrâneas. Com a presença de rochas solúveis e a ação do intemperismo químico por águas ácidas, ocorre dissolução da rocha e o desenvolvimento de feições cársticas.

Para um bom desenvolvimento do relevo cárstico Christofoletti (1980) afirma ser necessário a existência de algumas condições básicas, que são elas 1. Presença de rochas solúveis e

\footnotetext{
${ }^{1}$ Daniel dos Reis Cavalcante, Laboratório de Estudos Morfoestruturais e Pedológicos, Universidade Estadual do Ceará, FortalezaCE, Brasil

${ }^{2}$ Frederico de Holanda Bastos, Laboratório de Estudos Morfoestruturais e Pedológicos, Universidade Estadual do Ceará, Fortaleza-CE, Brasil
} 
fraturadas; 2. A presença de água, tanto por águas meteóricas como por ação fluvial; e por fim 3. Um considerável gradiente para o escoamento da água.

Os relevos cársticos, com suas morfologias superficiais e subterrâneas, de forma geral, foram gerados a partir de processos morfogenéticos ao longo do Quaternário (AULER; PILÓ; SAADI, 2005). Com isso, os relevos cársticos documentam importantes eventos geológicos e principalmente eventos paleoclimáticos.

Tricart e Cardoso da Silva (1961) afirmam que a aridez climática regional perturba o crescimento da vegetação, sendo apenas os mecanismos de intemperismo físico e a dissolução direta por águas meteóricas que predominam na morfogênese atual dos relevos cársticos em regiões de climas tropicais secos.

No carste em regiões áridas, em consequência da escassez da cobertura vegetal densa e solos pouco desenvolvidos, a quantidade de $\mathrm{CO}_{2}$ é muito pequena, o que acaba por limitar o desenvolvimento do carste. Consequentemente, se identificadas morfologias cársticas sobre essas áreas, deve-se interpretá-las como sendo formadas em períodos onde a precipitação era mais expressiva (ELORZA, 2008).

O carste carbonático no Brasil, conforme Auler, Piló e Saadi (2005) ocorre em áreas de rochas carbonáticas antigas, sendo em grande parte do Pré-Cambriano, onde seu desenvolvimento se deu em áreas tectonicamente estáveis com climas sazonais. Entretanto, se faz necessário diferenciar a idade da estrutura da idade do relevo cárstico, ou seja, esses relevos foram formados recentemente ao longo da era Cenozóica, porém suas estruturas podem datar do Pré-Cambriano até o período Cretáceo, podendo a rocha ser sedimentar ou metamórfica.

No Estado do Ceará os relevos cársticos ocorrem em rochas mais antigas, um bom exemplo é o relevo cárstico formado nos metacalcários da Formação Frecheirinha no setor NW do Estado, há também relevos cársticos formados em rochas mais recentes, sendo aqui destacados os relevos formados nos calcários cretáceos da Formação Jandaíra na bacia sedimentar do Apodi.

A área de estudo está inserida no domínio das depressões intermontanas e interplanálticas semiáridas com áreas de fraca decomposição de rochas, drenagens intermitentes sazonais e uma considerável irregularidade no volume global de precipitações (AB’SÁBER, 2003).

O clima no Estado do Ceará é um fator limitante para o desenvolvimento de relevos cársticos, alguns fatores que são de grande relevância para a morfogênese cárstica, tais como vegetação e solos, acabam por serem influenciados pelo clima, tanto pelos baixos totais pluviométricos quanto pelas elevadas temperaturas médias, onde a vegetação de caatinga e solos pouco desenvolvidos predominam. 
No município de Tejuçuoca, centro-norte do Ceará, se encontra uma das mais expressivas ocorrências de relevos cársticos do Ceará, com representações de diversas formas que caracterizam esse tipo de relevo. O carste em questão (Figura 1) localiza-se no extremo SW do município, contudo, no contexto atual, a área não possui um dos requisitos básicos para o desenvolvimento de relevos cársticos, que são condições de clima úmido, tendo em vista que seus totais pluviométricos giram em torno de $600 \mathrm{~mm}$.

O referido carste é pouco extenso, limitando-se a um afloramento de mármores vinculado à Unidade Independência. Estes relevos encontram-se na vertente setentrional da serra do Machado, no esporão da referida serra que, localmente, recebe o topônimo de serra da Catirina.

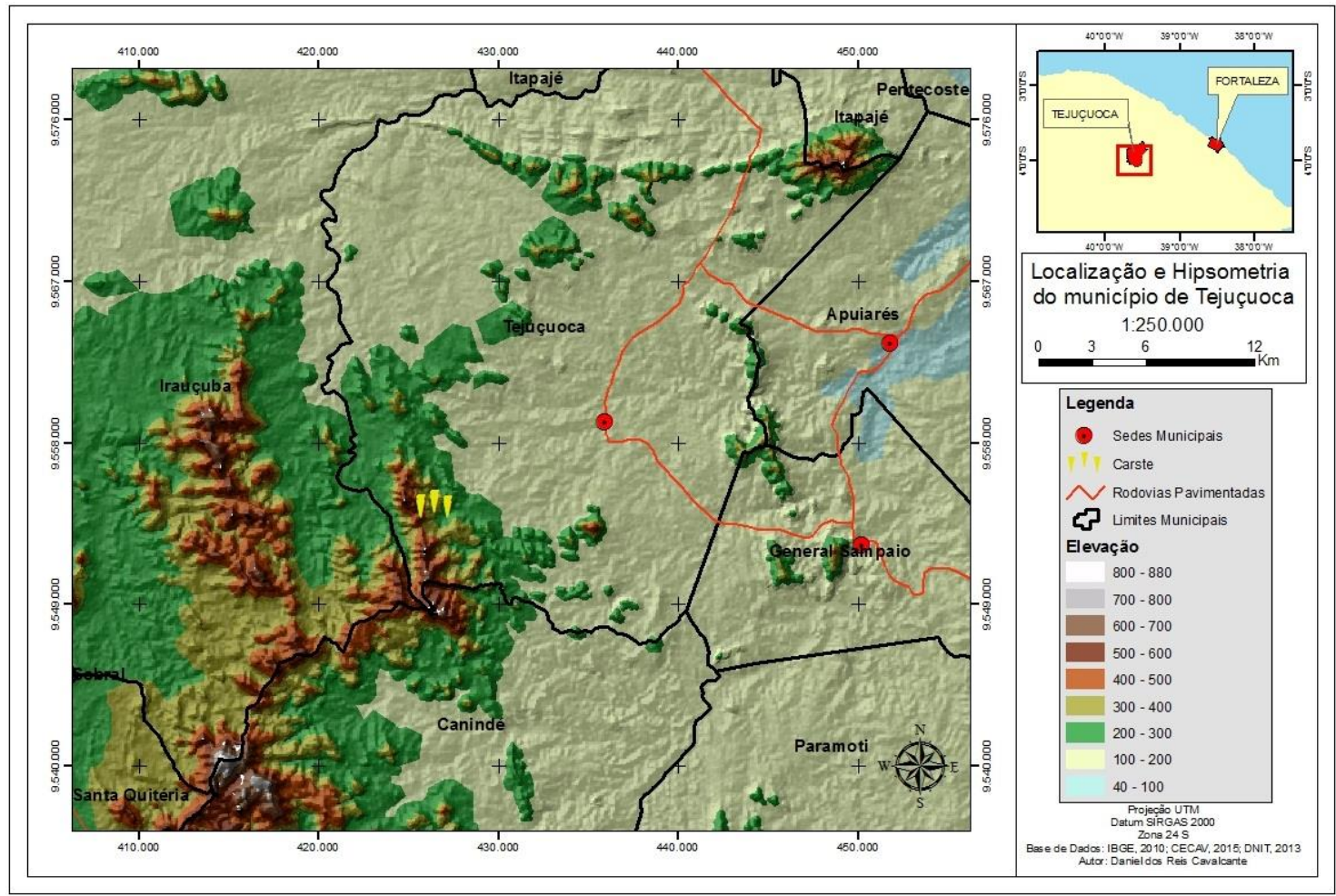

Figura 1: Localização e hipsometria da área de estudo. Fonte: Elaborado pelos autores (2016).

Face ao exposto, tem-se como objetivo do referido estudo destacar as influências paleoclimáticas ao longo do tempo geológico, sobretudo no Quaternário, junto à configuração atual do carste de Tejuçuoca.

\section{METODOLOGIA}

O referido estudo foi dividido em três etapas visando uma melhor organização e evolução da pesquisa para se chegar aos resultados almejados. A divisão das etapas se deu em levantamentos 
bibliográfico/cartográfico, trabalhos de campo, trabalhos de gabinete com auxílio de técnicas de geoprocessamento.

A primeira etapa consistiu em levantamentos bibliográficos de caráter interdiciplinar, onde buscou-se por estudos sobre relevos cársticos de forma geral e também em áreas áridas e semiáridas (TRICART e CARDOSO DA SILVA, 1961; CHRISTOFOLETTI, 1980; KOHLER, 1989; FORD e WILLIAMS, 2007; ELORZA, 2008), bem como estudos sobre paleoclimas no Nordeste brasileiro (JATOBÁ, 1993; WANG et al., 2004; CAVALCANTE, 2005; LIMA, 2008; SUGUIO, 2010; PIMENTEL, 2013).

No levantamento cartográfico os mapas mais consultados para uma melhor interpretação da área de estudo foram os mapas geológico da CPRM (BRASIL, 2003) na escala de 1:500.000 e o mapa morfoestrutural do Ceará e adjacências de Peulvast e Claudino Sales (2003) na escala de 1:500.000, além da utilização de imagens Shuttle Radar Topography Mission - SRTM da área de estudo.

Foram realizados também dois trabalhos de campo na área de estudo, onde se tentou identificar o contraste entre diferentes períodos do ano, sendo que o primeiro, no mês de outubro de 2015, foi marcado por um período de estiagem e o segundo, no mês de março de 2016, coincidiu com o período da quadra chuvosa. Esse contraste se fez necessário para se identificar os diferentes fatores que podem contribuir para a morfodinâmica cárstica, mesmo que de forma pouco expressiva.

Face ao exposto, o período de estiagem é marcado por temperaturas elevadas, mesmo dentro das grutas, e ausência de matéria orgânica devido o caráter xeromórfico da vegetação da caatinga. Já no período da quadra chuvosa pôde-se identificar a presença significativa de escorrimentos nas paredes das grutas, bem como temperaturas mais amenas. Também foram observadas a presença de matéria orgânica e água retida em alguns locais da estrutura, sobretudo nas pequenas depressões como nas kamenitzas, nesses casos é provável que haja atividade microbiológica e morfodinâmica limitadas espacialmente nesses locais por todo o período em que a matéria orgânica e a água ficam retidas.

Os trabalhos de gabinete foram de suma importância para a confecção da cartografia temática com auxílio das técnicas de geoprocessamento, nesta etapa também foi realizada a integralização dos dados obtidos em campo junto aos levantamentos bibliográficos/cartográficos visando o melhor entendimento da área.

\section{RESULTADOS E DISCUSSÃO}


Bailey (2004) se refere à paleoclima como climas que ocorreram no passado, sendo a paleoclimatologia responsável por estudos mais aprofundados sobre a temática. $\mathrm{O}$ autor ainda afirma que o clima tem papel significativo nos processos geomorfológicos, portanto, é necessário o conhecimento do clima atual e também dos climas do passado para uma boa interpretação do relevo.

Suguio (2010) ressalta que as causas das variações paleoclimáticas são complexas e são resultados da interação de fenômenos de caráter geológico, geofísico e astronômicos, sendo que ocorrem em diferentes escalas, tanto temporais quanto espaciais.

No período Quaternário houve alternâncias climáticas de forma cíclica, onde ocorreram alterações no quadro térmico e no regime pluviométrico, sendo que em regiões tropicais e subtropicais o efeito das alternâncias climáticas se deu de forma mais significativa no regime de chuvas (JATOBÁ, 1993).

Sobre os reflexos das glaciações no Nordeste brasileiro, Cavalcante (2005) cita como produto das glaciações o isolamento dos enclaves úmidos, que são refúgios de florestas outrora dominantes pela presença de climas úmidos e que se retraíram para as cimeiras de relevos residuais por causa da passagem de um clima úmido para um clima seco.

Nesse contexto, relevos cársticos são importantes documentos paleoclimáticos, sobretudo relevos cársticos bem desenvolvidos em regiões de climas áridos e semiáridos. Bigarella, Becker e Santos (2009) destacam que em terrenos calcários sob clima árido ou semiárido as feições cársticas são respectivamente pouco desenvolvidas ou ausentes e concluem afirmando que as feições cársticas que ocorrem nessas áreas podem ser explicadas como relíquias formadas durante regimes climáticos mais úmidos.

O relevo cárstico do município de Tejuçuoca apresenta uma morfologia notável, com expressivas feições exocársticas e endocársticas, ocorrendo presença de lapiás variados, kamenitzas, arcos, clarabóias entre outras formas externas. No que tange às feições endocársticas as estalagmites, estalactites e colunas são bem representativas, ocorrendo por quase todas as cavernas.

No entanto, a forma como o carste se apresenta, não reflete os processos predominantes do sistema morfoclimático atual. No caso, os mármores presentes na área e sua posição atual, que lhe confere um expressivo gradiente, são fatores favoráveis ao bom desenvolvimento de tal morfologia, porém, o clima semiárido com elevadas temperaturas médias diárias e um índice pluviométrico irregular, não permitem que a dissolução seja o principal processo morfodinâmico no carste em questão. 
O clima local é semiárido com poucas variações de temperatura ao longo do ano, cerca de $26^{\circ}$ a $29^{\circ} \mathrm{C}$ e baixos índices pluviométricos com extrema irregularidade ao longo do ano, sendo que o regime de chuva concentra-se em três meses, Fevereiro, Março e Abril, apresentando médias pluviométricas aproximadas de $600 \mathrm{~mm}$.

Diante de um contexto climático semelhante, Tricart e Cardoso da Silva (1961) afirmam que o clima onde está situada a gruta do Bom Jesus da Lapa é pouco favorável à carstificação, já que seus totais pluviométricos anuais oscilam entre 700 e $900 \mathrm{~mm}$. Cabe destacar que o contexto climático onde o carste de Tejuçuoca está inserido, se comparado ao exemplo de Bom Jesus da Lapa, tem-se condições pluviométricas ainda menos favoráveis à carstificação.

Ford e Williams (2007) afirmam que chuvas torrenciais aliadas à ausência de solos e o clima semiárido, fazem com que o escoamento fluvial seja total e a evaporação seja rápida, limitando assim o desenvolvimento do epicarste. Esse fato foi observado no carste em questão, constatando-se a ausência de solos e, consequentemente, do epicarste, além de uma vegetação local predominantemente arbustiva. Esses elementos têm papel fundamental na morfodinâmica cárstica, pois é onde se situa grande concentração de $\mathrm{CO}_{2}$ e indicam claramente mudanças no contexto morfoclimático regional com início de ciclos erosivos associados a climas mais secos.

No caso do carste de Tejuçuoca, é fato que o sistema morfoclimático atual não propicia condições necessárias para a morfogênese cárstica, entretanto, não se pode desconsiderar que exista, mesmo que de forma pouco expressiva, dissolução da rocha carbonática por águas meteóricas. No entanto, se faz necessário destacar o papel das oscilações climáticas ao longo do Quaternário para tentar justificar a presença de tal morfologia cárstica tão significativa.

Nessa conjuntura, Melo et al. (2005) enfatizam a importância dos eventos pretéritos, tanto climáticos quanto estruturais, para o entendimento da configuração atual dos relevos na superfície da Terra. Para o Nordeste do Brasil alguns eventos de oscilações climáticas foram verificados por Behling et al. (2000), Wang et al. (2004) e Lima (2008).

Behling et al. (2000) através de registro palinológico encontrado em amostras retiradas na plataforma continental leste do Estado do Ceará, possivelmente entre as cidades de Beberibe e Aracati, a cerca de $70 \mathrm{~km}$ da linha de costa, inferiram que a pluviosidade era mais expressiva nos períodos de 40, 33 e 24 mil anos A.P., sendo que a maior taxa de precipitação já registrada no Nordeste brasileiro ocorreu entre 15.500 e 11.800 anos A.P.. Os autores ainda afirmam que foi nesse período de maior taxa de precipitação que ocorreu a expansão das florestas úmidas.

Lima (2008) afirma que taxas de intemperismo e precipitação de óxidos de manganês têm utilidade para o entendimento dos paleoclimas. Com isso, através da análise de amostras de óxido de manganês, adquiridas entre os Estados de Pernambuco, Rio Grande do Norte, Paraíba e 
Ceará a autora sugeriu quatro picos onde as condições climáticas seriam quentes e úmidas (28; $10 ; 5,5 ; 1,5 \mathrm{Ma})$.

Por sua vez Wang et al. (2004), com auxílio de métodos de datações absolutas em espeleotemas e depósitos de travertinos adquiridos no Estado da Bahia, conseguiram inferir períodos de alta pluviosidade, onde os picos correspondem a 15, 39, 45 e 60 mil anos A.P. num intervalo de 210.000 mil anos, associados a deslocamentos meridionais da ZCIT.

Pimentel (2013) destaca que nos últimos 3.500 anos A.P. observou-se duas situações onde a precipitação no norte do Nordeste brasileiro sofreu uma notável redução, sendo a primeira situação em 2,5 - 3 mil anos A.P. e a segunda entre 1,5 - 2 mil anos A.P., o mais recente, por sua vez, representa o período mais seco registrado no norte do Nordeste brasileiro.

Relacionando os dados paleoclimáticos com o relevo cárstico do município de Tejuçuoca, fica claro que esse relevo teve seu mais expressivo desenvolvimento ao longo do Pleistoceno tardio, sobretudo no período entre 15.500 e 11.800 anos A.P., onde coincidiu com o período de maior taxa de precipitação já registrado para o Nordeste brasileiro (BEHLING, et al., 2000).

Sendo o clima fator determinante no condicionamento morfogenético, todas essas oscilações climáticas tiveram repercussões sobre o relevo regional, bem como no relevo cárstico em questão. As repercussões estão expressas em diferentes formas tanto exocársticas quanto endoársticas.

Os lapiás alveolares (Figura 3) identificados na área são excelentes testemunhos paleoclimáticos, tendo em vista que sua gênese se dá sob os solos (Epicarste). Nesse caso, com a ocorrência dessas feições por alguns setores, sobretudo nas partes mais baixas, pode-se afirmar que em períodos mais úmidos houve o desenvolvimento de mantos de intemperismo, justificando assim as morfologias arredondadas horizontalizadas a sub-horizontalizadas da área. 


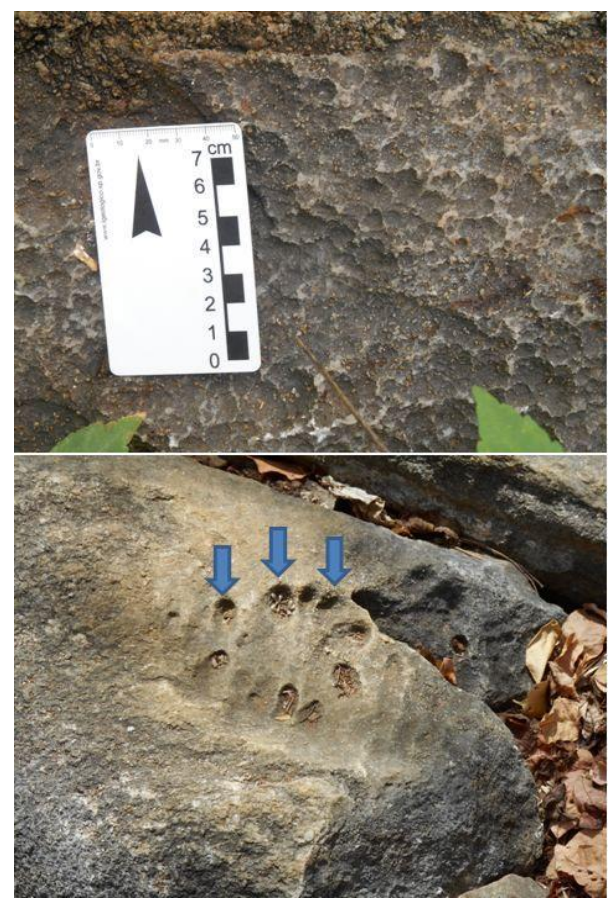

Figura 2: Lapiás alveolares indicando dissolução sob o solo. Fonte: Cavalcante (2015/2016).

As feições endocársticas, também conhecidas como espeleotemas, encontram-se bem desenvolvidas e se apresentam como importantes evidências paleoclimáticas no sertão cearense. As cavernas de origem epigênica abrigam diferentes morfologias que, de forma geral, lembram canyons com paredões escarpados.

Foi possível observar que as cavernas mais baixas têm espeleotemas mais desenvolvidos que as cavernas que se situam nos locais mais altos. Nas cavernas mais baixas identificou-se estalagmites, estalactites, cortinas, colunas, micro-represas de travertinos (Figura 4) entre outras formas. Já nas cavernas situadas nas áreas mais altas também foram encontradas essas feições, porém, de forma menos expressiva. 


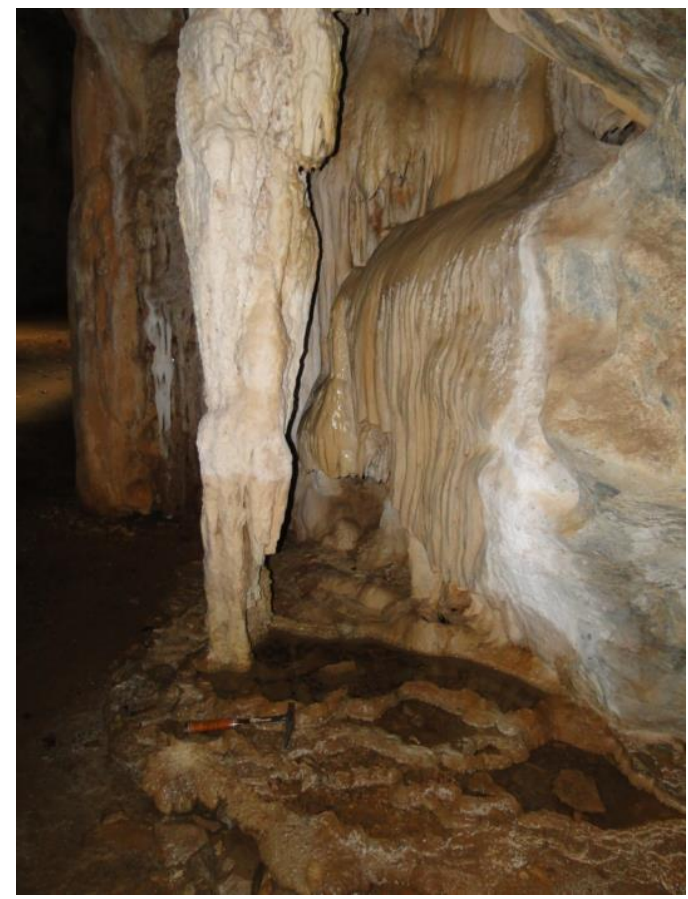

Figura 3: Micro-represa de travertino na base de uma coluna na Gruta do Sino. Fonte: Bastos e Cavalcante, 2016.

Destaca-se também que o carste de Tejuçuoca não é o único a apresentar essas condições nos sertões cearenses, há também relevos cársticos no município de Madalena, os identificados por Ab’Sáber (1979) na vertente oriental do maciço de Baturité no alto da serra do Cantagalo, na região sul do Ceará mais especificamente no município de Farias Brito e o paleocarste no município de Quixeré (JESUS et al., 2012) que também representa uma notável feição cárstica situada no semiárido cearense.

\section{CONSIDERAÇÕES FINAIS}

A ocorrência dos relevos cársticos no município de Tejuçuoca está ligado a fatores endógenos, principalmente os passivos e fatores exógenos, porém constata-se que o sistema morfoclimático atual não corresponde ao principal fator responsável pelo expressivo desenvolvimento das feições cársticas.

Nota-se que a atual configuração do carste possui estreitas relações com eventos paleoclimáticos, sobretudo do Pleistoceno, onde autores verificaram diversos picos de umidade ao longo dos últimos 200.000 anos A.P., tendo como principal repercussão o aumento das taxas de precipitação no Nordeste brasileiro.

Com isso, o carste de Tejuçuoca documenta importantes eventos climáticos nas suas diferentes feições morfológicas, sendo de grande necessidade estudos mais aprofundados buscando a compreensão da morfodinâmica atual e pretérita do relevo cárstico em questão. Cabe 
aqui destacar também a importância da geoconservação do patrimônio geomorfológico que a área abriga, tendo em vista seu potencial geoturístico e espeleoturístico.

\section{REFERÊNCIAS}

AB'SÁBER, A. N. Geomorfologia e Espeleologia. Espeleo-Tema, v. 12, p. 25-32, São Paulo, 1979.

Editorial, 2003.

Os domínios de natureza no Brasil: potencialidades paisagísticas. São Paulo: Ateliê

AUler, A. S.; PILÓ, L. B.; SAADI, A. Ambientes cársticos. In: SOUZA, C. R. G. et al. (Ed.). Quaternário do Brasil. Ribeirão Preto: Holos Editora, p. 321-342, 2005.

BAILEY, R. Palaeoclimate. In: Goudie, A. S. (Hrsg.). Encyclopedia of Geomorphology. Volume 1, Edition Routledge, p. 746-748, 2004.

BEHLING, H.; ARZ, H. W.; PÄTZOLD, J.; WEFER, G. Late Quaternary vegetational and climate dynamics in northeastern Brazil, inferences from marine core GeoB 3104-1.Quaternary Science Reviews, v. 19, n. 10, p. 981-994, 2000.

BIGARELLA, J. J; BECKER, R.D.; SANTOS, G.F. Estrutura e Origem das Paisagens Tropicais e Subtropicais. V. 1. $2^{\text {a }}$ Edição. Florianópolis: Editora da UFSC, 2009.

BRASIL. Companhia de Pesquisa de Recursos Minerais - CPRM. Atlas Digital de Geologia e Recursos Minerais do Ceará. Mapa na escala 1:500.000. Serviço Geológico do Brasil. Ministério das Minas e Energia. Fortaleza, 2003.

CAVAlCANTE, A. Jardins suspensos no Sertão. Scientific American Brasil, v. 32, p. 69-73, São Paulo, 2005.

CHRISTOFOLETTI, A. Geomorfologia. São Paulo: Blucher, 1980.

ELORZA, M. G. Geomorfología. Madrid: Pearson Educación, 2008.

FORD, D.; WILLIAMS, P. Karst hydrogeology and geomorphology. John Wiley \& Sons, 2007.

JATOBÁ, L. As mudanças climáticas do Quaternário e suas repercussões no relevo do Mundo Tropical. Coleção Mossoroense, Série B, n. 1238, p. 5-39, Mossoró, 1993.

JESUS, T. E. S.; REIS JÚNIOR, J. A.; CASTRO, D. L.; LIMA-FILHO, F.P. Imageamento digital de paleocavernas colapsadas com ground penetrating radar. Geologia USP. Série Científica, v. 12, n. 3, p. 71-84, 2012.

KOHLER, H. C. Geomorfologia cárstica na região de Lagoa Santa, MG. Tese (Doutorado) Universidade de São Paulo. São Paulo, 1989. 
LIMA, M. G. A História do Intemperismo na Província Borborema: Implicações Paleoclimáticas e Tectônicas. Tese (Doutorado) - Universidade Federal do Rio Grande do Norte. Natal, 2008.

MELO, M. S.; ClAUDINO-SALES, V.; PEULVAST, J. P.; SAADI, A.; MELLO, C. L. Processos e Produtos Morfogenéticos Continentais. In: SOUZA, C. R. G. et al. (Ed.). Quaternário do Brasil. Ribeirão Preto: Holos Editora, p. 258-275, 2005.

PEULVAST, J. P.; CLAUDINO SALES, V. Carta morfoestrutural do Ceará e áreas adjacentes do Rio Grande do Norte e da Paraíba. Nota explicativa. In: CPRM: Atlas digital de geologia e recursos minerais do Ceará. Mapas na escala 1:500.000. Serviço geológico do Brasil, Fortaleza, 2003.

PIMENTEL, F. V. Reconstrução da precipitação sobre o Nordeste brasileiro em função das temperaturas da superfície do mar durante o Holoceno. Dissertação (Mestrado) - Universidade Estadual do Ceará. Fortaleza, 2013.

SUGUIO, K. Geologia do quaternário e mudanças ambientais. São Paulo: Oficina de Textos, 2010.

TRICART, J.; CARDOSO DA SILVA, T. Um exemplo de evolução karstica em meio tropical sêco: o môrro de Bom Jesus da Lapa (Bahia). Boletim Baiano de Geografia, n. 5 e 6, p. 3-19, Salvador, 1961.

WANG, X.; AULER, A. S.; EDWARDS, R. L.; CHENG, H.; CRISTALLI, P. S.; SMART, P. L.; RICHARDS, D. A.; SHEN, C. C. Wet periods in northeastern Brazil over the past $210 \mathrm{kyr}$ linked to distant climate anomalies. Nature, v. 432, p. 740-743, 2004.

Recebido em: 14/08/2016

Aceito para publicação em: 01/10/2016 